\title{
Perioperative synbiotics administration decreases postoperative infections in patients with colorectal cancer: a randomized, double-blind clinical trial
}

\section{A administração perioperatória de simbióticos em pacientes com câncer colorretal reduz a incidência de infecções pós-operatórias: ensaio clínico randomizado duplo-cego}

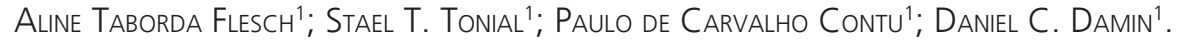

\section{A B S T R A C T}

\begin{abstract}
Objective: to evaluate the effect of perioperative administration of symbiotics on the incidence of surgical wound infection in patients undergoing surgery for colorectal cancer. Methods: We conducted a randomized clinical trial with colorectal cancer patients undergoing elective surgery, randomly assigned to receive symbiotics or placebo for five days prior to the surgical procedure and for 14 days after surgery. We studied 91 patients, 49 in the symbiotics group (Lactobacillus acidophilus $10^{8}$ to $10^{9} \mathrm{CFU}$, Lactobacillus rhamnosus $10^{8}$ to $10^{9}$ CFU, Lactobacillus casei $10^{8}$ to $10^{9} \mathrm{CFU}$, Bifi dobacterium $10^{8}$ to $10^{9} \mathrm{CFU}$ and fructo-oligosaccharide (FOS) 6g) and 42 in the placebo group. Results: surgical site infection occurred in one (2\%) patient in the symbiotics group and in nine (21.4\%) patients in the control group $(p=0.002)$. There were three cases of intraabdominal abscess and four cases of pneumonia in the control group, whereas we observed no infections in patients receiving symbiotics $(p=0.001)$. Conclusion: the perioperative administration of symbiotics significantly reduced postoperative infection rates in patients with colorectal cancer. Additional studies are needed to confirm the role of symbiotics in the surgical treatment of colorectal cancer.
\end{abstract}

Keywords: Synbiotics. Infection. Colorectal Surgery. Colorectal Neoplasms. Clinical Trial.

\section{INTRODUCTION}

$\mathrm{D}$ espite the recent advances in colorectal surgery, such as the use of minimally invasive surgery techniques and improvements in postoperative care, the incidence of postoperative infectious complications remains high. Surgical site infection (SSI) is particularly common, with incidence rates varying from $5 \%$ to $26 \% 1,2$. This seems to result, in part, from microflora imbalances and interruption of the intestinal barrier ${ }^{3,4}$. Studies of different gastrointestinal procedures, including pancreaticoduodenectomy, hepatobiliary resection and liver transplantation, suggest that the use of symbiotics may represent a promising approach for the prevention of postoperative infections ${ }^{5-7}$. Symbiotics are compounds formed by the combination of prebiotics and probiotics. Prebiotics are nondigestible food components that selectively alter the growth and activity of colonic bacteria. Probiotics are viable bacteria used to regulate the balance of intestinal microflora ${ }^{8,9}$. Although the colon is an important reservoir for commensal microorganisms, the use of symbiotics in colorectal surgery is controversial10-12.

The objective of this study was to evaluate the effect of perioperative administration of symbiotics on the incidence of postoperative infection in patients submitted to a potentially curative surgical resection of colorectal cancer.

\section{METHODS}

This is a randomized, double-blinded, placebo-controlled trial. The study was conducted by the Coloproctology Service of the Porto Alegre Clinics Hospital between June 2013 and April 2015. Patients with histologically proven colorectal adenocarcinoma with indication of elective and potentially curative colorectal resection were considered eligible to participate in the study. Exclusion criteria were pregnancy, patient's difficulties regarding adequate understanding of the

1 - Federal University of Rio Grande do Sul, Post-Graduation Program in Surgical Sciences, Porto Alegre, RS, Brazil. 
study, neoadjuvant treatment (chemotherapy and radiotherapy), previous use of products with prebiotic, probiotic and/or symbiotic function or fiber modulus, and refusal to participate. We also excluded from the analysis patients with tumors that were considered non-resectable during surgery and those who had other organs resected concomitantly (uterus, bladder liver, spleen).

The present study was performed after approval by the Ethics in Research Committee of the Porto Alegre Clinics Hospital, protocol number 12.0284. We obtained an informed consent term from all patients before inclusion. This work was entered in the ClinicalTrials.gov registry (identifier NCT01468779) and followed the recommendations of the Consolidated Standards of Reporting Trials (CONSORT 2010).

\section{Groups of study}

Preoperative assessment of the patients included a complete clinical history and physical examination, carcinoembryonic antigen dosage, colonoscopic examination, computed tomography of the abdomen and pelvis and chest X-ray and/or computed tomography of the chest. In addition, all patients underwent subjective global assessment (SGA) and anthropometric assessments ${ }^{13}$.

We randomly allocated patients in the intervention group (symbiotic) or in the control group (placebo). Both were given two sachets twice a day containing the active substance (intervention group) or placebo (control group) for five days before the surgical procedure and for 14 days after surgery. The intervention group received sachets containing Lactobacillus acidophilus NCFM (109), Lactobacillus rhamnosus HN001 $\left(10^{9}\right)$, Lactobacillus paracasei LPC-37 $\left(10^{9}\right)$, Bifidobacterium lactis HNO19 $\left(10^{9}\right)$ and fructo -oligosaccharides (FOS) $6 \mathrm{~g}$. The control group received sachets containing $96 \%$ maltodextrin $100 \%$ (6g). The sachets for both groups had the same appearance and the substances had the same color and flavor. The pharmacist, exclusively involved in the manufacturing of the symbiotics and placebo, randomized patients using a computer-generated sequence of numbers.
Both the investigators and the patients were blinded as to to group allocation until the end of the test. However, blinding could be disrupted if patients had severe adverse events that might be related to the product being investigated.

On the day before surgery, all patients underwent routine bowel preparation. They also received intravenous gentamicin and metronidazole one hour before surgery.

\section{Clinical variables}

Postoperative infection was defined as infection occurring within 30 days of surgery. Infections were classified as incisional (surgical wound), organ/space (where surgery was performed) or at a distant site (urinary tract infection, pneumonia). The length of hospital stay was defined as the number of days elapsed from surgery to discharge. Deaths occurring within 30 days of surgery were considered surgical.

\section{Statistical analysis}

The sample size was based on a previous study that found a reduction in infection rates from $40 \%$ to $12.5 \%$ after administration of symbiotics ${ }^{14}$. For a statistical power of $80 \%$ and an expected sampling loss rate of $10 \%$, the sample size would be 90 patients. The sample size calculations were done with the COMPARE2 1.72 software.

We analyzed the data with the Statistical Program for Social Sciences program version 20.0 (SPSS Inc., Chicago, IL, USA, 2008) for Windows. We studies continuous variables using the Kolmogorov-Smirnov test. For the bivariate analysis of categorical variables, we used the Pearson Chi-square test or the Fisher's Exact Test. For continuous variables, when comparing two independent groups, were applied the Student's t or the Mann Whitney $U$ test . We set the level of significance at $p<0.05$.

\section{RESULTS}

We initially included one hundred patients in the study. Of these, were excluded nine: four with unresectable tumors and five patients who required concomitant resection of other organs. After exclusions, the 
intervention group (symbiotics) consisted of 49 patients and the control group (placebo), of 42 . Both groups were similar, showing no statistical differences in demographic and clinical characteristics (Table 1).

Table 1. Variables evaluated.

\begin{tabular}{|c|c|c|c|c|c|}
\hline \multirow{3}{*}{ Variáveis } & \multicolumn{4}{|c|}{ Groups } & \multirow[t]{3}{*}{$P$} \\
\hline & \multicolumn{2}{|c|}{ Intervention $(\mathrm{n}=49)$} & \multicolumn{2}{|c|}{ Control $(n=42)$} & \\
\hline & $\mathrm{n}$ & $\%$ & $\mathrm{n}$ & $\%$ & \\
\hline Age (years) & 64.5 & 11.4 & 61.1 & 13.4 & 0.192 \\
\hline BMI $\left(\mathrm{kg} / \mathrm{m}^{2}\right)$ & 26.57 & 3.8 & 25.7 & 5.3 & 0.353 \\
\hline Gender & & & & & 0.542 \\
\hline Female & 31 & 54.8 & 23 & 63.3 & \\
\hline Male & 18 & 45.2 & 19 & 36.7 & \\
\hline Diabetes & 9 & 21.4 & 12 & 24.5 & 0.924 \\
\hline $\begin{array}{l}\text { Cardiovascular } \\
\text { Disease }\end{array}$ & 29 & 60.4 & 19 & 36.6 & 0.264 \\
\hline Lung Disease & 5 & 10.2 & 5 & 11.9 & 1.0 \\
\hline Other & 16 & 36.7 & 12 & 28.6 & 0.847 \\
\hline Albumin & & & & & 0.100 \\
\hline Below 3.5mg/dl & 8 & 16.3 & 2 & 4.8 & \\
\hline $\begin{array}{l}\text { Greater than or } \\
\text { equal to } 3.5 \mathrm{mg} / \\
\text { dl }\end{array}$ & 41 & 83.7 & 40 & 95.2 & \\
\hline ASA & & & & & 0.259 \\
\hline | & 8 & 16.3 & 12 & 28.3 & \\
\hline$\|$ & 35 & 71.4 & 28 & 66.7 & \\
\hline III & 6 & 12.2 & 2 & 4.8 & \\
\hline IV & 0 & 0 & 0 & 0 & \\
\hline Ostomies & 22 & 44.9 & 20 & 47.6 & 0.961 \\
\hline Rehospitalization & 5 & 10.20 & 5 & 11.9 & 1.0 \\
\hline Type of surgery & & & & & 0.872 \\
\hline Open & 43 & 87.75 & 35 & 83.33 & \\
\hline $\begin{array}{l}\text { Laparoscopic/ } \\
\text { Robotic }\end{array}$ & 6 & 12.24 & 7 & 16.66 & \\
\hline Tumor location & & & & & 1.0 \\
\hline Rectum & 28 & 53.8 & 24 & 57.1 & \\
\hline Colon & 21 & 42.9 & 18 & 42.9 & \\
\hline Tumor stage & & & & & 0.146 \\
\hline | & 14 & 28.6 & 11 & 26.2 & \\
\hline$\|$ & 20 & 40.8 & 20 & 47.6 & \\
\hline III & 14 & 28.6 & 6 & 14.3 & \\
\hline IV & 1 & 2 & 5 & 11.9 & \\
\hline $\begin{array}{l}\text { Subjective Global } \\
\text { Assessment }\end{array}$ & & & & & 0.764 \\
\hline A & 43 & 87.8 & 35 & 83.3 & \\
\hline B & 6 & 12.2 & 7 & 16.7 & \\
\hline
\end{tabular}


Only one patient in the symbiotics group presented surgical wound infection, while nine cases were diagnosed in the control group $(p=0.002)$. There was also a significant difference between the groups in relation to other infectious complications. While we observed three cases of intraabdominal abscess and four cases of pneumonia in the control group, we diagnosed no cases in the symbiotics group $(p=0.001)$.

The incidence of noninfectious postoperative complications such as nausea, vomiting, abdominal distension, ileus, diarrhea or constipation was not different between the study groups $(p=0.161)$. The mean hospitalization time was 11.2 days for the patients in the symbiotics group and 12.69 days for the patients in the control group was, with no statistical significance. There were no significant differences between the groups regarding mortality rates and re-hospitalization.

\section{DISCUSSION}

Recent clinical studies have evaluated the effect of immunomodulatory diets with probiotics and symbiotics on the incidence of infections related to different gastrointestinal surgeries. Promising results were demonstrated in resections of the pancreas, liver and esophagus ${ }^{5-7,15}$. Regarding colorectal resections, however, the results so far have been conflicting due to differences in the populations studied, type of surgery, type of probiotics and symbiotics used, and analysis methodology 11,12,16,17.

Our study is the first to evaluate the effect of symbiotics not only on cancer patients undergoing minimally invasive colorectal surgery, including robotic and laparoscopic resections, but also in patients undergoing conventional open colorectal surgery. In this sense, we prospectively evaluated a homogeneous population of patients with histologically confirmed colorectal adenocarcinoma submitted to elective and potentially curative oncological resection. We decided not to include patients undergoing surgery for benign colorectal diseases, considering the particular nutritional and immunological aspects of patients with colorectal cancer. Patients submitted to resection of multiple adjacent organs were excluded, as these surgeries are generally more extensive and related to increased morbidity. In addition, patients whose tumors were considered non-resectable were excluded. As shown in table 1, after patients randomization, we ended the study groups with similar clinical and demographic characteristics.

Because of the nature of colorectal surgery, infectious complications, especially wound infections, are extremely common, with a negative impact on quality of life, length of hospitalization, and costs. In this study, the perioperative use of symbiotics significantly reduced the incidence of wound infection.

Among the functions of the symbiotic compounds, the best characterized is the increase of the resistance of the strains against pathogens. Probiotic cultures compete with pathogenic microorganisms, whose growth is inhibited by the production of organic acids (lactate, propionate, butyrate and acetate), reinforcing the natural defense mechanisms of the body ${ }^{18-20}$. Modulation of the intestinal microbiota by probiotic microorganisms occurs through a mechanism called "competitive exclusion" and the strains that beneficially act in such cases are Bifidobacterium bifidum, Lactobacillus rhamnosus, Saccharomyces boulardii and Lactobacillus plantarum ${ }^{21}$.

The effect of probiotics on the immune response has also been demonstrated. Evidence in in vitro systems and animal models suggest that probiotics stimulate nonspecific and specific immune response. These effects are mediated by the activation of macrophages through an increase in cytokine levels and natural killer cell (NK) activity. The intestinal mucosa is the body's first line of defense against pathogenic invasions and action of toxic elements. After ingestion, the antigens encounter the GALT (gut-associated lymphoid tissue), which represents a mechanism of protection against pathogens. It also prevents the proteic hyperstimulation of the immune response through a mechanism known as tolerance to ingested content. The main protective mechanism of GALT is the humoral immune response mediated by IgA secretion, which prevents the entry of potentially harmful antigens, while at the same time interacting with pathogens of the mucosa without increasing the damage. Numerous studies have shown that some probiotic 
strains can increase S-IgA and modulate the production of cytokines involved in the regulation, activation, growth and differentiation of immune cells. It should be emphasized that the beneficial effects of probiotics on the immune system occur without triggering a harmful inflammatory response. However, not all lactic acid bacterial strains are equally effective. The immune response may be increased when one or more probiotics are consumed simultaneously and act synergistically, as appears to be the case with Lactobacillus given in conjunction with Bifidobacterium (SAAD), which we used in this study ${ }^{22-24}$.

In our study, the use of symbiotics also reduced the incidence of remote infections such as pneumonia, which only occurred in the control group. This finding is in line with the results of a meta-analysis conducted by Yang et al. ${ }^{25}$ that analyzed 28 randomized trials involving 2511 patients undergoing different abdominal surgeries, including esophagectomies, pancreatectomies, hepatectomies, liver transplants and colectomies. The incidence of infections was lower among patients receiving symbiotics than in controls, particularly for respiratory, urinary, and wound infections. Hospitalization time was also shorter in patients receiving symbiotics. In our study, however, there was no difference between groups in relation to the length of hospital stay.

He et al. ${ }^{11}$ carried out a specific meta-analysis to estimate the probiotic/symbiotic treatment efficacy in patients undergoing colorectal resection. Only six randomized clinical trials involving 361 patients were included. Two studies aimed at preoperative use of probiotics or symbiotics, a study on postoperative treatment, and three evaluated pre and postoperative treatment. In addition to the differences in the products used, there was also heterogeneity between studies in the inclusion criteria and the types of sur- gery performed. The pre or perioperative administration of symbiotics had a positive effect on the incidence of total surgical infections and pneumonia.

More recently, Komatsu et al. ${ }^{9}$ performed a randomized, controlled, unicentric study, including patients undergoing elective laparoscopic colorectal surgery. A total of 379 patients were randomly assigned to two groups: 173 in the symbiotics group and 206 in the control group. After applying selection criteria, 362 patients (168 of the symbiotic group and 194 for the control group) were considered eligible for the study. Infection occurred in 29 (17.3\%) patients of the symbiotics group and in 44 (22.7\%) of the control group. According to the authors, symbiotics were not an effective treatment to reduce the incidence of infectious complications after colorectal resection.

In our study, we included not only patients submitted to minimally invasive surgeries, but also conventional open surgeries, which represented the majority of our cases. One of the potential advantages of minimally invasive surgery is less surgical trauma, with less acute inflammatory response and immune disorders. All infection cases occurred among patients undergoing open surgery, which suggests that the symbiotics effect is more important in this type of surgery.

We observed, therefore, that the perioperative administration of symbiotics in patients submitted to elective surgery for colorectal cancer significantly reduced the rates of postoperative infection. Our results suggest that preoperative and postoperative oral ingestion of symbiotics may represent a promising strategy to prevent surgical infections in patients with colorectal cancer. Additional studies are needed to confirm the role of these microorganisms in colorectal surgery. 


\title{
R E S U M O
}

\begin{abstract}
Objetivo: avaliar o efeito da administração perioperatória de simbióticos na incidência de infecção de ferida operatória em pacientes operados por câncer colorretal. Métodos: ensaio clínico randomizado de pacientes com câncer colorretal submetidos à cirurgia eletiva e aleatoriamente designados para receberem simbióticos ou placebo por cinco dias antes do procedimento cirúrgico e por 14 dias após a cirurgia. Noventa e um pacientes foram estudados: 49 para o grupo de simbióticos (Lactobacillus acidophilus $10^{8}$ a $10^{9}$ UFC, Lactobacillus rhamnosus $10^{8}$ a $10^{9}$ UFC, Lactobacillus casei $10^{8}$ a $10^{9}$ UFC, Bifi dobacterium $10^{8}$ a $10^{9}$ UFC e fruto-oligosacarídeos (FOS) $6 \mathrm{~g}$ ) e 42 para o grupo placebo. Resultados: infecção de sítio cirúrgico ocorreu em um (2\%) paciente no grupo de simbióticos e em nove (21,4\%) pacientes no grupo controle $(p=0,002)$. Três casos de abscesso intra-abdominal e quatro casos de pneumonia foram diagnosticados no grupo controle, enquanto não foram observadas tais infecções em pacientes que receberam simbióticos $(p=0,001)$. Conclusão: a administração perioperatória de simbióticos reduziu significativamente as taxas de infecção pós-operatória em pacientes com câncer colorretal. Estudos adicionais são necessários para confirmar o papel dos simbióticos no tratamento cirúrgico do câncer colorretal.
\end{abstract}

Descritores: Simbióticos. Infecção. Cirurgia Colorretal. Neoplasias Colorretais. Ensaio Clínico.

\section{REFERENCES}

1. Fusco Sde FB, Massarico NM, Alves MV, Fortaleza CM, Pavan EC, Palhares Vde C, et al. [Surgical site infection and its risk factors in colon surgeries]. Rev Esc Enferm USP. 2016;50(1):43-9. Portuguese.

2. de Lissovoy G, Fraeman K, Hutchins V, Murphy D, Song D, Vaughn BB. Surgical site infection: incidence and impact on hospital utilization and treatment costs. Am J Infect Control. 2009;37(5):387-97.

3. Howard DD, White CQ, Harden TR, Ellis CN. Incidence of surgical site infections postcolorectal resections without preoperative mechanical or antibiotic bowel preparation. Am Surg. 2009;75(8):659-63.

4. Fooks LJ, Gibson GR. Probiotics as modulators of the gut flora. Br J Nutr. 2002;88 Suppl 1:S39-49.

5. Rayes N, Seehofer D, Hansen S, Boucsein K, Müller $A R$, Serke $S$, et al. Early enteral supply of lactobacillus and fiber versus selective bowel decontamination: a controlled trial in liver transplant recipients. Transplantation. 2002;274(1):123-7.

6. Kanazawa $H$, Nagino $M$, Kamiya $S$, Komatsu $S$, Mayumi T, Takagi $K$, et al. Synbiotics reduce postoperative infectious complications: a randomized controlled trial in biliary cancer patients undergoing hepatectomy. Langenbecks Arch Surg. 2005;390(2):104-13.

7. Sommacal HM, Bersch VP, Vitola SP, Osvaldt AB. Perioperative synbiotics decrease postoperative complications in periampullary neoplasms: a randomized, double-blind clinical trial. Nutr Cancer. 2015;67 (3):457-62.
8. Flesch AG, Poziomyck AK, Damin DC. The therapeutic use of symbiotics. Arq Bras Cir Dig. 2014;27(3):2069.

9. Komatsu S, Sakamoto E, Norimizu S, Shingu Y, Asahara $T$ et al. Efficacy of perioperative synbiotics treatment for the prevention of surgical site infection after laparoscopic colorectal surgery: a randomized controlled trial. Surg Today. 2016;46(4):479-90.

10. Denipote FG, Trindade EB, Burini RC. [Probiotics and prebiotics in primary care for colon cancer]. Arq Gastroenterol. 2010;47(1):93-8. Portuguese.

11. He D, Wang HY, Feng JY, Zhang MM, Zhou $Y$, Wu $\mathrm{XT}$. Use of pro-/synbiotics as prophylaxis in patients undergoing colorectal resection for cancer: a metaanalysis of randomized controlled trials. Clin Res Hepatol Gastroenterol. 2013;37(4):406-15.

12. Horvat $M$, Krebs $B$, Potrc $S$, Ivanecz $A$, Kompan L. Preoperative synbiotic bowel conditioning for elective colorectal surgery. Wien Klin Wonchenschr. 2010;122 Suppl 2:26-30.

13. Detsky AS, McLaughlin JR, Baker JP, Johnston $N$ Whittaker S, Mendelson RA, et al. What is subjective global assessment of nutritional status? JPEN J Parenter Enteral Nutr. 1987;11(1):8-13.

14. Sommacal HM, Bersch VP, Vitola SP, Osvaldt AB. Perioperative synbiotics decrease postoperative complications in periampullary neoplasms: a randomized, double-blind clinical trial. Nutr Cancer. 2015;67(3):457-62.

15. Tanaka K, Yano M, Motoori M, Kishi K, Miyashiro I, Ohue $M$, et al. Impact of perioperative administration of synbiotics in patients with 
esophageal cancer undergoing esophagectomy: a prospective randomized controlled trial. Surgery. 2012;152(5):832-42.

16. Anderson $A D$, McNaught $C E$, Jain PK, MacFie J. Randomised clinical trial of synbiotic therapy in elective surgical patients. Gut. 2004;53(2):241-5.

17. Reddy BS, Macfie J, Gatt M, Larsen CN, Jensen SS, Lese TD. Randomized clinical trial of effect of synbiotics, neomycin and mechanical bowel preparation on intestinal barrier function in patients undergoing colectomy. Br J Surg. 2007;94(5):54654.

18. Chan YK, Estaki M, Gibson DL. Clinical consequences of diet-induced dysbiosis. Ann Nutr Metab. 2013;63 Suppl 2:28-40.

19. Kinross JM, Markar S, Karthikesalingam A, Chow A, Penney N, Silk $D$, et al. A meta-analysis of probiotic and synbiotic use in elective surgery: does nutrition modulation of the gut microbiome improve clinical outcome? JPEN J Parenter Enteral Nutr. 2013;37(2):243-53.

20. Gibson GR, Roberfroid MB. Dietary modulation of the human colonic microbiota: introducing the concept of prebiotics. J Nutr. 1995;125(6):1401-12.

21. Barrenetxe J, Aranguren P, Grijalba A, MartínezPeñuela JM, Marzo F, Urdaneta E. Modulation of gastrointestinal physiology through probiotic strains of Lactobacillus casei and Bifidobacterium bifidum. An Sist Sanit Navar. 2006;29(3):337-47.
22. Delcenserie $V$, Martel $D$, Lamoureux $M$, Amiot J, Boutin Y, Roy D. Immunomodulatory effects of probiotics in the intestinal tract. Curr Issues Mol Biol. 2008; 10(1-2):37-54.

23. Gaudier E, Michel C, Segain JP, Cherbut C, Hoebler C. The VSL\#3 probiotic mixture modifies microflora but does not heal chronic dextran-sodium sulfateinduced colitis or reinforce the mucus barrier in mice. J Nutr. 2005;135(12):2753-61.

24. Gillor O, Etzion A, Riley MA. The dual role of bacteriocins as anti- and probiotics. Appl Microbiol Biotechnol. 2008;81(4):591-606.

25. Yang Z, Wu Qsimbioticos, Liu Y, Fan D. Effect of perioperative probiotics and synbiotics on postoperative infections after gastrointestinal surgery: a systematic review with meta-analysis. JPEN J Parenter Enteral Nutr. 2016:148607116629670. [Epub ahead of print].

Received in: 07/06/2017

Accepted for publication: 20/07/2017

Conflict of interest: none.

Source of funding: none.

\section{Endereço para correspondência:}

Daniel C. Damin

E-mail: damin@terra.com.br / ddamin@hcpa.edu.br 